\title{
Vocabulary size revisited: the link between vocabulary size and academic achievement
}

Article

Accepted Version

Treffers-Daller, J. and Milton, J. (2013) Vocabulary size revisited: the link between vocabulary size and academic achievement. Applied Linguistics Review, 4 (1). pp. 151-172. ISSN 1868-6311 doi: https://doi.org/10.1515/applirev-20130007 Available at https://centaur.reading.ac.uk/29879/

It is advisable to refer to the publisher's version if you intend to cite from the work. See Guidance on citing.

To link to this article DOI: http://dx.doi.org/10.1515/applirev-2013-0007

Publisher: De Gruyter

Publisher statement: The final publication is available at www.degruyter.com

All outputs in CentAUR are protected by Intellectual Property Rights law, including copyright law. Copyright and IPR is retained by the creators or other copyright holders. Terms and conditions for use of this material are defined in the End User Agreement.

www.reading.ac.uk/centaur

\section{CentAUR}


Central Archive at the University of Reading

Reading's research outputs online 


\title{
Vocabulary size revisited: the link between vocabulary size and academic achievement
}

\author{
James Milton (Swansea University) and Jeanine Treffers-Daller (University of Reading)
}

\begin{abstract}
Many researchers have tried to assess the number of words adults know. A general conclusion which emerges from such studies is that vocabularies of English monolingual adults are very large with considerable variation. This variation is important given that the vocabulary size of schoolchildren in the early years of school is thought to materially affect subsequent educational attainment. The data is difficult to interpret, however, because of the different methodologies which researchers use. The study in this paper uses the frequencybased vocabulary size test from Goulden et al (1990) and investigates the vocabulary knowledge of undergraduates in three British universities. The results suggest that monolingual speaker vocabulary sizes may be much smaller than is generally thought with far less variation than is usually reported. An average figure of about 10,000 English words families emerges for entrants to university. This figure suggests that many students must struggle with the comprehension of university level texts.
\end{abstract}

\section{Introduction}

There are many reasons for wanting to study the development of vocabulary knowledge. Anglin $(1993,2)$ lists just some of these. Vocabulary knowledge provides the essential building blocks of language and without vocabulary neither language production nor language comprehension is possible. According to Bates and Goodman (1997) it is vocabulary knowledge which drives the development of grammar. There is also considerable evidence that vocabulary size in infancy is a strong predictor linguistic and cognitive abilities at four years (Feldman, Dale, Campbell, Colborn, Jurs-Lasky, Rockette \& Paradise, 2005) and even at eight years (Marchman \& Fernald 2008). In addition, vocabulary size is clearly linked to the acquisition of competence in reading (see for example Ouellette 2006; Snow, Tabor, Nicholson, Kurland 1995) and, in turn, to success in school (see for example Biemiller \& Boote 2006; Bornstein \& Haynes 1998; Tymms, Merrell \& Henderson 1997).

Vocabulary knowledge, and in particular the size of the lexicon has been the subject of systematic research for over a century. Despite this, even basic information such as the size of monolingual speakers' vocabularies, and the rate at which vocabulary is acquired in childhood, remains something of a mystery. The history of this research is characterised by figures for vocabulary size, usually among English speaking educated or college students, that can vary by a factor of 20. One of the earliest estimates, Kirkpatrick (1891), concluded that a US citizen with a common-school education had a vocabulary of about 10,000 words, and a college graduate between 20,000 and 100,000 words. Fifty years of research served to extend the estimate. Seashore and Eckerson (1940) suggested undergraduates have vocabularies of 155,000 words, and Hartmann (1946) 200,000 words. More recent estimates can still be large and both Aitchison (2003) and White, Graves and Slater (1990) suggest 60,000 words among educated monolingual speakers, but they can also be much smaller and Goulden et al (1990) suggest 17,200 words. D'Anna, Zechmeister and Hall (1991) using a self-reporting method conclude that college students know 16,785 words and of these 14,076 words could actually be defined. The smallest estimate (Milton 2009) suggest that British undergraduates may have a defining vocabulary as small as 9,000 word families. 
The current study was motivated in the first place by the large discrepancies between the estimates of vocabulary size found in the literature, and in the second place by our own observations that students often struggle to understand the academic texts they are being asked to read. It is entirely possible that undergraduate students experience difficulties in reading because they do not know a sufficient number of words to understand what they read. We therefore think it is timely to take a fresh look at the number of words known by adult monolinguals. As we think it is students' vocabulary size which may explain, at least in part, why they are struggling to read academic texts, we also investigate the relationship between students' vocabulary sizes and the grades they obtain for their modules and/or their final degree classification. Before going into our own study we briefly review different ways to measure vocabulary knowledge (section 1), the extant literature on vocabulary in L1 and L2 acquisition (sections 2 and 3), and the link between vocabulary knowledge and reading (section 4). We then present our methodology in section 5, the results in section 6 and in the discussion and conclusion (section 7) we go into the implications of our findings for theories of vocabulary development in L1 and L2 acquisition.

\subsection{Measuring vocabulary size}

There is no standard testing method for calculating vocabulary size and the absence of this goes a long way to explain the enormous variation in the vocabulary size estimates and rates of progress among English speaking monolinguals which are reported. A principal cause of variation is how the words being counted are defined: should every different form and meaning of a word be counted separately, or should base or root words be counted together with inflections and derivations as a single lemma or word family. The smaller word counts such as D'Anna et al (1991) and Goulden et al (1990) count word families, so regular inflections, jump, jumped and jumping, and regular and transparent affixation relating form and meaning, develop and developer, would all be counted within one word family. The larger vocabulary counts tend to treat these derived forms in particular separately, as in separate dictionary entries, which must inflate the word count. It can be argued that counting words as lemmas or word families reflects the way words are stored and processed by the brain and can therefore give more meaningful results as to the scale of learning involved in growth a lexicon. Counting words as lemmas or word families is now a standard in studies of second and foreign language acquisition and such techniques are thought to give reliable and meaningful results. However, even with this approach there are further thorny questions as to whether names and proper nouns should be included as words or not. If they are excluded then the word knowledge estimates are likely to be reduced.

A second factor affecting the count is how word knowledge is defined. Are words known if they are simply recognised as words or is it essential to be able to attach a meaning or definition to the word as well, and if a word has several meanings should all of them be known or is one sufficient to meet the criterion of a known word? The choice made should also affect the word count since evidence, particularly from second language learners, is that the words that can be accurately defined are usually a smaller sub-set of the words that are recognised where a meaning cannot always be called readily to mind (Milton 2009). The more recent vocabulary size estimates, for example, Nagy and Herman (1987), Goulden et al (1990) and D'Anna et al (1991) attempt to assess definition vocabulary rather than merely recognition vocabulary which may explain the smaller estimates that result. However, as Anglin (1993) points out, too stringent use of this definition approach might lead to 
underestimation of vocabulary size particularly in children since the metalinguistic skills involved in definition only evolve with time.

A third factor, how word knowledge is being tested or calculated, can also influence the apparent size which emerges. Nagy and Herman (1987) extrapolate from the word loading of school textbooks to draw conclusions about the size of vocabularies the readers of these must have. The school text books they examined, it seems, contain 88,500 different word families between grades 3 and 9 (Nagy and Anderson 1984) and it is presumed that school children must, by and large, know these or a very significant proportion of them. This presumption appears not to be tested on the learners themselves. White et al (1990) use a multiple choice format and D'Anna et al (1991) a self-reporting format to test knowledge of sample words more directly but these approaches must, as D'Anna et al acknowledge, involve some overestimation although the scale of this is not known. Goulden et al (1990) use a checklist format where, in principle at least, self-reporting is moderated by the need for test-takers to check they can define some of the words. It is not clear how rigorously this moderation was performed, and what effect this had on the sizes which emerged, so there may be overestimation in this calculation also. The effect of the choice of method can be seen in that the estimates by Nagy and Herman are probably three of four times the size of those of D'Anna et al and Goulden et al (1990) even though they attempt to use the same unit of count, and the same definition of knowledge.

Finally, the source of words selected for testing can influence the word count. Estimates based on dictionary sampling are dependent in particular on the size of the dictionary as Lorge and Chall (1963) point out. D'Anna et al suggest this explains the kind of variation seen when comparing Nagy and Herman's (1987) estimate of 40,000 words known by college seniors, and Hartmann's (1946) 200,000 words known by undergraduates. To avoid this kind of problem, another approach to word selection draws words from specified levels in frequency counts and this is the approach taken by Goulden et al who assess words taken from the most frequent 25,000 word families found in Thorndike and Lorge's (1944) frequency lists, and also present in Webster's Third New International Dictionary (1961) as the basis of their estimate. This test is then supplemented with a second test of word families present in Webster's but sufficiently rare to fall outside this 25,000 word frequency range. They suggest that only testees whose score on the first test exceeds 15,000 need bother with this second test. For further details on different methods to assess second language vocabulary, we refer to Milton (2009) and Read (2007).

Estimates of vocabulary size need to be treated with great caution because of the methodologies involved. An uncritical acceptance of some of the larger figures raises questions about how such volumes of words can be acquired. Goulden et al (1990), for example, point out that Diller's (1978) estimate of lexical growth in childhood implies that children must encounter an average of 60 new and different words, with sufficient repetition and context for learning to occur, each day and every day throughout secondary school for the rate of growth he describes to be attained. This kind of estimate is so large that it is not clear at all how learning on this scale can occur. The following section addresses this issue.

\subsection{Vocabulary development in L1 acquisition}

If estimates of the end point of vocabulary learning can vary so much, it is not surprising that estimates of the rate at which vocabulary is acquired in childhood can also vary. Diller (1978) suggests that secondary school children learn 20,000 words a year. Miller and Gildea (1987) 
suggest 5,000 words per year for school learners. There is one figure, however, that is repeated frequently and has gained the status of being a standard, and this is the figure that children learn approximately 3,000 new words annually (for example, Graves 2006, 14; Nagy 1988, 30; Marzano 2004, 63). Beck and McKeown refine this estimate by claiming that only about 300 of these 3,000 words are explicitly taught to learners at school (cited in Duke and Carlisle 2011, 206-07).

This figure seems largely to be drawn from a single study by Nagy and Herman (1987) although White et al (1990) imply this figure through a different methodology. More conservatively Schmitt and McCarthy $(1997,7)$ extrapolate the vocabulary size estimates of Goulden et al (1990) and estimate that 1000 words per year are acquired through childhood. Biemiller and Boote (2006: 44) come to the same conclusion and claim that American children add 1,000 new word meanings per year after grade 2 (when children are six years old). Typically developing children have acquired 6,000 root word meanings by the end of grade two, although there is a great deal of variation: children in the lowest quartile have no more than 4,000 root words and those in highest quartile know 8,000 root words. Because of these large discrepancies, Biemiller and Boote strongly argue the case for vocabulary teaching in primary classrooms in order to bridge the gap in knowledge between children with a smaller and those with more developed vocabularies.

It is thought likely that vocabulary sizes vary so much because the quantity and quality of the input children receive differ greatly. In L1 acquisition, the main source of input is of course verbal in the first instance, but there is considerable evidence that reading contributes to word learning too (Nagy, Herman, and Anderson 1985). Nation and Meara (2002: 38) also consider that it is not so much deliberate study but rather "learning from meaning-focused input, that is learning incidentally through listening and reading, [which] accounts for most first language vocabulary learning". Some evidence for the contribution incidental learning can make for learning words in L1 acquisition can be found in Shu, Anderson, and Zhang's (1995) of American and Chinese children. They found that the probability of learning an unknown word from context as a by-product of reading (i.e. incidentally) in the first language is .10 for American children and .08 for Chinese children. While the chance of learning words incidentally thus appears to be limited, the cumulative effect of word learning through reading could be quite considerable, according to the authors, provided the children are active readers. The relevance of vocabulary size measures becomes significant here since it is unknown whether children or other language users have the capacity for effective reading without minimum levels of vocabulary knowledge. The number of words readers need to understand different kinds of text and the vocabulary gains second language learners can make during reading will be developed further in section 3 and it is a purpose of the research in this paper to investigate whether our university level learners have the lexical knowledge to easily handle the academic texts they study.

\subsection{Vocabulary knowledge of bilinguals and L2 learners}

Because of the growing numbers of individuals who grow up with more than one language or learn another language later in life, we briefly want to address a few key issues relating to the vocabulary size of bilinguals and the development of vocabulary knowledge in a second language.

It has often been observed that the vocabulary of bilingual children is smaller in each language than that of monolinguals (see Bialystok 2001; Bialystok, Luk, Peets and Yang 
2010, Oller and Eilers 2002 for overviews), and similar findings are reported for studies in which adult monolinguals and bilinguals are compared (Craik \& Bialystok, 2006; Fernandes, Craik, Bialystok, \& Kreuger 2007). This can probably be attributed to the fact that bilinguals use their languages for different purposes in daily life and they therefore do not need translation equivalents for all words in their two languages. In addition, most bilinguals are dominant in one or the other language: at the level of vocabulary language dominance is often visible in that oral or written texts produced by bilinguals are not equally rich in both languages (Treffers-Daller 2011).

As Meara (1980: 221) has pointed out, "most learners identify the acquisition of vocabulary as their greatest single source of problems". This is particularly true for adults, according to McLaughlin (1978: 324), who points out that vocabulary development is the "prime task of adult L2 learners". Hatch (1978, cited by McLaughlin 1978) agrees and explains that "this is why adults carry dictionaries, not grammars, when they travel in foreign countries. Schmitt (2007: 827) develops this further and notes that mastering a "sufficient" number of words constitutes a particular challenge for learners of English because there are purportedly more words in this language than in other languages. Recent research has provided some evidence with respect to the question what constitutes a sufficient number of words for different tasks. For participating in an everyday conversation it is assumed a learner needs 2,000-3,000 of the most frequent English words (Adolphs and Schmitt 2003), whilst s/he needs 5,000 words to begin to read authentic texts (Schmitt 2007) and around 10,000 for starting an academic degree course (Hazenberg and Hulstijn 1996). Nation (2006) also investigated the vocabulary size of a group of highly educated L2-users of English who were studying advanced degrees through the medium of English and found that they knew around 8,000 to 9,000 wordfamilies. If all these estimates are correct, the vocabulary size of educated L2-users would therefore be around half that of educated monolinguals, assuming the latter know around 17,000 words. It is questionable, however, whether monolinguals do indeed possess such huge volumes of vocabulary, and whether they are really needed even in university study.

There is also a considerable body of evidence about incidental acquisition of words by L2 learners during reading. While the results of these studies do not converge upon a single figure, there appears to be a growing consensus that learners do not pick up a huge number of words from reading (see Pellicer-Sánchez and Schmitt 2010). The percentages of novel words learned whilst reading mentioned by Waring and Nation (2004) range from $5.8 \%$ to $25 \%$, but the percentages are not directly comparable due to the use of different exposure techniques and measurement tools. According to Waring and Nation (2004) about one tenth of words will be learned from reading in the L2. It is also clear that different dimensions of word knowledge (e.g. recognition of the form, collocations, derivates, ability to translate, etc.) have different retention rates, that fewer words are retained in a delayed post test than in an immediate post test and that multiple encounters increase the chance of learning a word. Therefore, as Waring and Nation (2004: 103) put it, "the incidental learning of vocabulary is best considered as a cumulative process where learners build up knowledge of a word through repeated encounters over a reasonable period of time."

\subsection{Vocabulary knowledge, reading and academic achievement}

In the absence of another, and better, explanation of adults' presumed enormous vocabulary sizes, it is generally assumed that they are acquired indirectly from the learners' language environment and that '...reading may be the single largest source of vocabulary growth' (Nagy, 1988, 30). This implies that the reading and language environment which a child 
grows up in can have a very significant effect on the size of their lexicon and this, in turn, can have significant implications.

Particularly important is the effect this is believed to have on subsequent school attainment (Biemiller 2001, Hart and Risley, 2003). Children who grow up without exposure to a lexically rich language environment, which access to reading material can greatly assist, are at risk of beginning their education with a lexical disadvantage. Studies show that children entering school do display considerable variation (Biemiller and Slonim 2001; Hart and Risley 1995) where lexically advantaged children can have a vocabulary double that of lexically disadvantaged children. The manner in which this affects subsequent school performance is known as the Matthew effect for reading (Stanovich, 1986), where students with high vocabularies at school entry can read better and so read more and so grow larger vocabularies than those with smaller vocabularies. It is not clear from research evidence that the Matthew effect for reading can be demonstrated (Shaywitz et al 1995) but, as Graves (2006) notes, there have been a number of attempts to bolster the vocabulary knowledge of lexically disadvantaged children, for example, Dialogic Reading (Whitehurst et al 1988), Text Talk (Beck and McKeown 2001), Direct and Systematic Instruction (Biemiller 2003), and Anchored Instruction (Juel and Deffes 2004). These interventions are all predicated on the idea that the volume of vocabulary in text books requires enormous lexical learning for learners to handle it.

There is some work on the lexical loading of texts which are set for university students to read, and the levels of vocabulary which are required for comprehension more generally, where much smaller estimates of the vocabulary needed by learners have been arrived at. Hazenberg and Hulstijn (1996) suggest that in Dutch a minimum of 10,000 words plus proper nouns and names would be needed for comprehension of university level texts. Nation (2006) in a study of the lexis in novels and newspapers concludes that knowledge of the 8,000 to 9,000 most frequent word families in the British National Corpus would be required to achieve the $98 \%$ coverage required for comprehension. The choice of $98 \%$ coverage is supported by research (Hu and Nation 2000) which suggests that learners with lexical levels of knowledge giving this degree of coverage do indeed achieve comprehension levels which greater coverage levels do little to supplement. This figure of 9 to 10,000 word families is repeated in both studies and appears small compared to the tens of thousands of words which Nagy and Herman (1987) suggest are needed.

To sum this up, therefore, the data we have on the vocabulary sizes of learners is hard to interpret. So too is the data we have which links vocabulary size to the ability to handle texts successfully in school or university. However, the idea that the lexicons of monolinguals are very large seems sufficiently well-entrenched for a body of theory of how this is learned to have grown up around it. This theory has significant effect on the practice of education even if it is not incontestably demonstrated. The time seems right to approach once more the question of vocabulary size using the techniques and insights which have proved useful in study foreign language vocabulary learning. Some of the more recent studies, it seems to us, are moving towards the kind of methodology which will allow replication and reliable normative scores to emerge. The word family, for example, appears to be accepted unit of count, reflecting the way words are stored in the mental lexicon and allowing consistent and believable figures for size and growth to emerge. Defining knowledge as the ability to link a word to meaning is likewise a common feature of the more recent studies. Goulden et al's use of word selection based on frequency counts also offers the opportunity for an approach to size estimate which avoids many of the pitfalls found in purely dictionary counts. 


\subsection{The aims of this research}

The intention in this paper, therefore, is to reappraise the vocabulary size of students attending three British universities above by using the Goulden et al test of vocabulary size. To our knowledge, vocabulary size estimation on a significantly large sample of British university students has not been reported in the academic literature. Almost all previous studies are based on speakers of American English. The study is intended to:

- Use results from the test to look for frequency effects in learning and therefore establish which words tend to be known by adult monolinguals.

- Form an estimate of the size of defining vocabulary which adult monolinguals have, and the degree of variation in size which exists.

- Form an estimate of the annual growth in vocabulary which learners undergo.

- Investigate whether reading habits can be seen to relate to the vocabulary size of the testees.

- Investigate whether the link between vocabulary size and educational attainment can be observed in undergraduate performance and the degree class obtained by subjects.

\section{Method}

\subsection{The subjects}

178 undergraduate students from three British universities (City University, Swansea University and the University of the West of England, Bristol) took part in the study. The students were following degree courses in Humanities at Swansea and UWE and a degree course in Speech and Language Therapy at City University. Students in Britain usually follow a three year degree programme and testees were drawn from the first year at City University and Swansea and from all three years at UWE.

Table 1. Overview of participants in the study

\begin{tabular}{|l|l|}
\hline year & number \\
\hline 1 & 133 \\
\hline 2 & 32 \\
\hline 3 & 19 \\
\hline
\end{tabular}

Students were tested in the first semester of their study year. Not all the students tested were monolingual English speakers. There were 17 who categorised themselves as bilingual, using two or three languages including English routinely in the home. A further 10 students categorised themselves as L2-users. The handling of these students in the calculations of vocabulary size is explained in the results section.

\subsection{The test}

The students took a fifty item test taken from Goulden et al (1990) drawn from Webster's Third New International Dictionary (1961) and selected to be a representative sample of the 25,000 most frequent words on Thorndike and Lorge's (1944) frequency lists. There are five sub-tests to this test and 10 words are selected from each of the first 5,000 word bands in this list. Additionally students took the additional test of 221 words chosen by Goulden et al as a sample of the words in Webster's which fell outside the 25,000 word range. This gives the same sampling rate as the items in the first, frequency based test. 
This test is a self-reporting checklist test where, in Goulden et al's original version, the testees are asked to read through the lists and mark the words they know the meaning of. Once they have done this they are asked to go back through the list in frequency order and for the last five words they tick (the least frequent therefore) they are asked to provide a synonym or explanation which should be checked in a dictionary. If they find an explanation is not correct then this word is discounted from the size calculation and the learners checks next least frequent word they marked. The correctness of every word marked is not checked therefore and self-reporting of this kind, as noted by D'Anna et al (1991) can result in overestimation of knowledge. To try to avoid the over-estimation in this study we have asked the testees to provide a synonym, explanation or illustration of use for every word they identify in the test. These responses have then been checked by the authors for correctness. The test used is provided in the Appendix.

To calculate vocabulary size, the total number of words correctly explained in the first, frequency-based, part of the test has been multiplied by 500, and the number of words correctly explained in the second part of the test is multiplied by 100. The sum of these two figures provides the estimate of size.

\subsection{Investigating reading habits}

In addition to the vocabulary tests, students were asked to complete a short questionnaire to elicit quantifiable information about the volumes of reading they engaged in, to allow comparison between subjects. Subjects were asked to estimate firstly the number of books they read per year, and secondly the number of newspapers they read each week. In both cases the more books they read and the more papers they read, then the greater is the likely exposure to infrequent vocabulary, much less available in speech than in writing, giving subjects an enhanced opportunity for vocabulary growth. It was expected that subjects who read newspapers daily, and who read books extensively, would score higher on the vocabulary tests than those who did not and that a general relationship in the form of a positive correlation between volumes of reading and vocabulary size would emerge from the data.

\section{Results}

\section{Frequency effects}

The data demonstrates a very strong frequency effect where vocabulary knowledge preponderates in the levels of most frequent word occurrence. This effect is summarised in table 2 and Figure 1.

Table 2. Number of words known at different frequency bands

\begin{tabular}{|l|c|l|l|l|}
\hline & Means per level & SD & $\max$ & $\min$ \\
\hline $1-5000$ & 4675 & 447 & 5000 & 3000 \\
\hline $5001-10000$ & 3298 & 685 & 5000 & 2000 \\
\hline $10001-15000$ & 825 & 642 & 3000 & 0 \\
\hline $15001-20000$ & 789 & 554 & 2500 & 0 \\
\hline $20001-25000$ & 93 & 250 & 1500 & 0 \\
\hline Words beyond 25000 & 139 & 169 & 700 & 0 \\
\hline
\end{tabular}




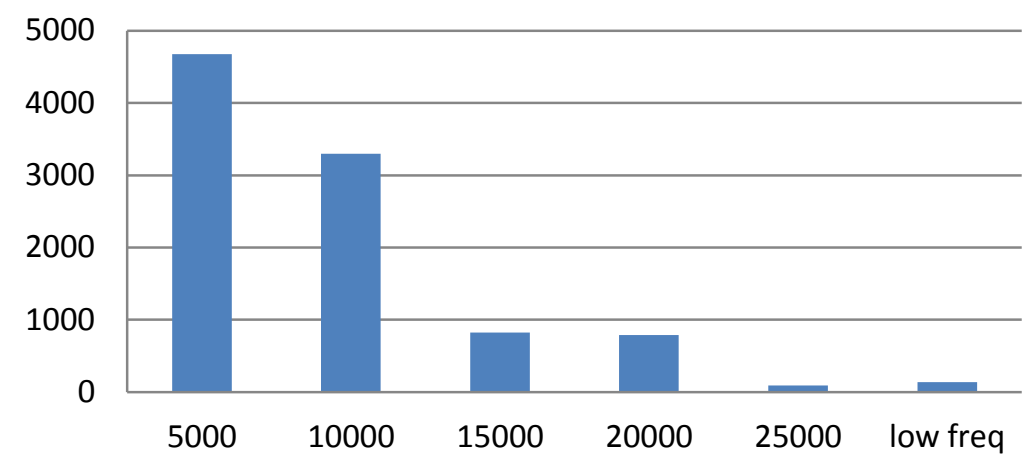

Figure 1. Number of words known at different frequency bands.

A Friedman analysis suggests the differences between the means at the five $\mathrm{x} 5000$ word levels of testing is statistically significant $\left(\chi^{2}=614.388\right.$, asymp. Sig. $\left.=.000\right)$.

\subsection{Vocabulary and multilinguality}

The vocabulary size scores for learners would were monolingual, bilingual and who designated themselves as speakers of English as a foreign language are given in Table 3.

Table 3. Number of monolingual, bilingual and EFL learners among the informants

\begin{tabular}{|l|l|l|l|}
\hline & $\mathrm{n}$ & Mean vocab score & SD \\
\hline Monolingual English & 151 & 9813.01 & 1866.23 \\
\hline Bilingual English & 10 & 9450.00 & 1450.86 \\
\hline EFL & 17 & 6988.24 & 2605.97 \\
\hline
\end{tabular}

As might be expected the group with the largest mean vocabulary size is the monolingual English speakers. The bilingual English speakers have a slightly smaller vocabulary size (see also section 3). The speakers of English as a foreign language have the smallest mean vocabulary size. An ANOVA confirms that the differences in these means is statistically significant $\mathrm{f}(2,175)=16.43$, sig $<.001$. A Tukey test confirms that the scores of the EFL speakers are statistically distinct from the other two and for this reason these 17 sets of data have been excluded from further analysis.

\subsection{Vocabulary size on entry to university}

The mean scores for level 1 students at the three institutions are given in Table 4

Table 4. Mean scores per university

\begin{tabular}{|l|l|l|l|}
\hline & $\mathrm{n}$ & Mean vocab score & SD \\
\hline UWE Bristol & 21 & 10090.48 & 1866.23 \\
\hline City University & 40 & 9900.00 & 1450.86 \\
\hline Swansea University & 52 & 9509.62 & 2605.97 \\
\hline Mean for all & 113 & 9755.75 & 1976.06 \\
\hline
\end{tabular}

The mean scores vary slightly but the differences in the means are not statistically significant, $\mathrm{f}(2,110)=0.8080$, sig $=.448$. For the purposes of this study the institutions cannot be distinguished in terms of the vocabulary size of the students entering. The mean score on entry suggests that the informants acquired on average about 500 to 550 words per year throughout childhood and adolescence before entering university. 


\subsection{Vocabulary growth at university}

A summary of vocabulary size scores at all three university levels is given in Table 5

Table 5. Mean vocabulary size according to university levels

\begin{tabular}{|l|l|l|l|}
\hline level & $\mathrm{n}$ & Mean vocab size & SD \\
\hline 1 & 113 & 9755.75 & 1976.06 \\
\hline 2 & 30 & 9793.33 & 1598.72 \\
\hline 3 & 18 & 10855.56 & 1961.25 \\
\hline
\end{tabular}

The scores suggest that vocabulary size increases during students' time studying at university, and comparison of level 1 and level 3 scores suggests growth continues to grow at 500 to 550 words per year on average. However, an ANOVA indicates that the differences in the means is not significant $F(2,158)=2.708$, sig. $=0.070$.

\subsection{Relating vocabulary size with reading habits}

If extensive reading is the key to the growth of the large vocabularies which educated learners are thought to possess then some sort of link between vocabulary size and the volumes of reading which are undertaken might reasonably be expected. Level 1 participants in this study were asked to estimate how often they read daily newspapers and how many books they thought they read in a typical year, in an attempt to see whether such a link exists. Correlations between these variables and vocabulary size are recorded in Table 6. We have chosen spearman's rho for this analysis as the two reading variables were not normally distributed.

Table 6. Spearman correlations between reported reading habits and vocabulary size

\begin{tabular}{|l|l|c|}
\hline & $\begin{array}{l}\text { Books read per year } \\
\text { (spearman's rho) }\end{array}$ & $\begin{array}{l}\text { Newspapers read per week } \\
\text { (spearman's rho) }\end{array}$ \\
\hline Vocabulary size & 0.174 & -.030 \\
\hline
\end{tabular}

In the case of students' reported reading of books, the correlations are small and not statistically significant. An even smaller and negative correlation was found for the number newspapers students read per week and this is also not statistically significant.

\subsection{Vocabulary size and academic performance}

Vocabulary size scores from students have been correlated with mean scores from academic modules, and therefore for level 3 students with their degree classification, in order to test for a relationship between vocabulary size and academic performance at university level. As both variables were normally distributed, we have chosen a Pearson correlation to compute these results. The correlations are presented in Table 7.

Table 7. Correlations between vocabulary size and students' average marks on their modules.

\begin{tabular}{|l|l|l|}
\hline & $\begin{array}{l}\text { Pearson } \\
\text { correlations with } \\
\text { total Vocab size }\end{array}$ & $\begin{array}{l}\text { Pearson correlations with } \\
25,000 \text { word test only }\end{array}$ \\
\hline Level 1 & 0.387 & 0.390 \\
\hline Level 2 & 0.477 & 0.473 \\
\hline
\end{tabular}


All correlations are significant at the 0.05 level and suggest a modest connection between vocabulary size and academic performance.

\section{Discussion}

\subsection{Vocabulary size and testing}

The results of this study suggest that university students aged 18 or 19 have smaller vocabulary resources than the figures in previous studies have suggested. Our results reveal that students know in the region of 10,000 words on entry to university and approximately 11,000 words in the final year. These figures ought to be directly comparable with the estimations made by Nagy and Hermann (1987) since both estimates are based on a calculation based on counting word families, but they are much smaller. The figures are also smaller than estimates by D'Anna et al. (1991) and Goulden et al and these are also based on the same unit of count although D'Anna et al (1991) recognise their estimate must contain some over-estimation. The smaller result is probably a product of the methodology used where the students are expected to demonstrate their knowledge of the words they claim to recognise thereby avoiding much of the problem associated with self-assessment, or with extrapolation from the vocabulary loading of course books.

Students were requested in the test rubric not to use guesswork and appear to have generally abided by this but there are occasions where the testees have entirely the wrong idea of the word they identify as known. Incorrect definitions include anamnestic (a snake), nubile (quick on one's feet), hostile (make welcome) and precede (to carry on). The testees who took part in this study incorrectly defined an average of 4.2 items each suggesting an overestimation of perhaps 2000 words and bearing out D'Anna and Zechmeister's observation that their estimates must be overstate the size of the lexicons their testees have. This does not completely explain the difference between the estimate in this study and other such as D'Anna et al and Goulden et al, but knowing that the results would be checked may have reduced guesswork in this study.

The results also confirm in monolingual adults the kind of frequency effects which are commonly observed in second language learners of English. There is a pronounced trend for more frequent vocabulary to be better known than less frequent vocabulary. This tendency is seen in Figure 1 where knowledge is concentrated in the two highest frequency bands. This lends credence to the idea that a frequency based test will capture and characterise vocabulary knowledge very effectively, as it does in many foreign language vocabulary size tests (e.g. Nation 2001 and Meara and Milton 2003). A vocabulary size test based on a modern corpus such as the BNC might also help alleviate the problems associated with the selection of words from dictionaries where the estimates produced will inevitably be a function of the size of the dictionary and where many of the entries, being historic or highly specialised, will fail to characterise the nature of modern, general language use. Further studies using such a revised test based on a corpus such as the BNC might well be fruitful and make an important step towards a consistent and reliable methodology for estimating vocabulary knowledge in monolingual adults.

\subsection{Variation and academic performance}


A further feature of the results is the absence of the high degrees of variation noted in previous studies and which are thought to explain differences in academic performance. The standard deviations which emerge suggest that the vocabulary sizes of the testees are pretty consistent. The overwhelming majority of scores are concentrated within 2000 words either side of the mean. There is nothing like the tenfold variation reported among college graduates reported by Kirkpatrick, nor even the two-fold differences which are reported to characterise school entrants in North America (Biemiller and Slonim 2001). Nonetheless, the limited differences in vocabulary size which do emerge among university students in UK appear to have some modest connection with the academic scores and the degree class which students finally obtain. Students with larger vocabularies tend to score higher in their assignments and exams and to obtain higher degree classifications than those with smaller vocabularies. The relationship may not be directly causal, of course. University classifications are intended to be based on subject knowledge and the insight and interpretation of that knowledge, and one might expect vocabulary size to impact only marginally on this ability. And yet, a correlation does emerge. The nature of this relationship begs further investigation.

One possible explanation of how and why vocabulary size can affect degree class at university emerges from the scale of vocabulary knowledge noted in this study. It appears that learners enter university with 9,000 to 10,000 words on average and this this observation suggests they ought to struggle with the lexis of the textbooks and other academic works they are required to read. 9,000 words is reported as a minimum level of vocabulary knowledge for the ability to handle English language newspapers (Nation 2006), and Konstantakis's (2010) examination of the lexical loading of business studies textbooks and articles suggest that much larger vocabulary sizes might be required for the easy handling of academic texts. This fits with our own observation of undergraduate students who often report they find the reading requirement of their courses difficult to carry out and that a quality newspaper like The Guardian is a difficult read.

\subsection{Lexical uptake, reading and implications for the theory of vocabulary learning}

The results in this study suggest that monolinguals acquire on average approximately 500 words per year in the time up to entry to university. While the results at university are not completely clear a comparison of first and last year vocabulary size scores suggests that they continue to acquire vocabulary at something like this rate during university education. This is nothing like the 3,000 words per year which is reported in so much of the literature on vocabulary acquisition in children, and even further away from the 20,000 words a year reported by Diller (1978). Our initial interpretation of this conclusion is that the volume of learning which emerges in this study is far more believable than in previous estimates. It extrapolates to about one or two words a day. These volumes of learning can easily be explained by explicit learning or even explicit teaching. Indeed, there are reports of explicit vocabulary learning in schools which are of precisely this order (Duke and Carlisle 2011). Therefore, this conclusion challenges the idea that volumes of vocabulary in a monolingual's lexicon are so large that the explanation for growth can only be satisfactory explained by implicit learning.

The explanation for the implicit acquisition of large quantities of vocabulary, presumably through reading (Nagy, 1988) has given rise to a much quoted theory of acquisition: the Matthew effect. However, the results of this study also fail to find the kind of relationship which a Matthew effect would produce. There appears to be no correlation of vocabulary size with reading habits, at least as far as students' reports of their reading of books and 
newspapers is concerned. It is possible, of course, that correlations between students' reading habits and their academic performance did not become significant because our measure of reading habits was rather crude. This conclusion, that a Matthew effect for reading cannot be demonstrated, bears out the conclusion of previous studies (for example Shaywitz et al 1995) which also fail to demonstrate this effect. This conclusion is also in line with studies which show that the percentage of words learned through reading is very limited (Waring and Nation 2004; Pellicer-Sánchez and Schmitt 2010). This suggests that the impact of implicit learning on a person's total vocabulary size needs to be re-examined and reconsidered.

\section{Conclusion}

The principal general conclusion to be drawn from this study is that the idea that vocabularies are huge probably needs to be laid to rest. University level monolingual English speakers arrive at university knowing, on average, about 10,000 words families. Of course, learning 10,000 lexical items before you get to university still represents an immense learning task but this total is no longer so large it that it defies reasonable explanation for its acquisition. It is a figure which suggests an uptake of about 500 words per year; a thoroughly achievable task. This in turn challenges explanations of vocabulary growth which rely on implicit learning and a huge uptake of vocabulary from extensive reading in particular. The figures for growth suggested here can be explained, as in second language learning, by explicit learning systems. There is even literature which suggests these kinds of volumes are learned by children from school textbooks in particular. Another idea that is challenged by the results of this study is that second speakers are very different in the lexical resource they have available when compared to speakers for whom English is their first (and only) language. Good second and foreign language speakers appear to have vocabularies comparable in size and often larger than their monolingual peers. Of course, they may use this resource differently, but simple vocabulary size need not be the source of any problems which second language learners display.

One effect of these smaller volumes of vocabulary, and the modest variation around the 10,000 figure which the average speakers appear to have, is that many university students much be at or below the cusp of the kind of vocabulary size which is required for the easy comprehension of university level texts. Complex texts such as academic articles can be quite densely packed with infrequent vocabulary and without this vocabulary comprehension is impaired with all the ramifications for study that this will have. Student achievement may, potentially, be explained as much by vocabulary size as by academic ability it would seem.

A study of this kind, which challenges perceived wisdom in so many ways, is pregnant with possibilities for further research and investigation. The sample in this study is comparatively small so a repetition of the study with a larger and more diverse sample of monolingual university students is sure to be useful. Cross-sectional and longitudinal studies of learners across the age ranges, starting in schools, would be useful to investigate whether the number of words monolinguals learn per year is as large as 2000, as reported in studies discussed in this paper, or in fact much smaller and closer to 500, as the results of our study suggest. It may be there are surges and plateaus in learning which currently we have little idea of. Repetition using a more rigorously designed test based on modern corpora and frequency lists would be ideal. We therefore need a standardised measurement tool so that the figures we all refer to in this field of study are more easily comparable. This would make possible further investigation not attempted in this study such as the effect of gender or subject differences in vocabulary size. 


\section{References}

Adolphs, Svenja \& Norbert Schmitt. 2003. Lexical coverage of spoken discourse. Applied Linguistics. 24(4), 425-438.

Aitchison, Jean. 2003. Words in the mind: An introduction to the mental lexicon. (3rd edition). Oxford and New York: Basil Blackwell.

Anglin, Jeremy M. 1993. Vocabulary development: A morphological analysis. Monographs of the Society for Research in Child Development, 58(10), Serial No. 238.

Beck, Isabel L. \& Margaret McKeown. 1991. Social studies texts are hard to understand: Mediating some of the difficulties. Language Arts, 68, 482-490.

Bialystok, Ellen. 2001. Bilingualism in development: Language, literacy, and cognition. New York: Cambridge University Press.

Bialystok, Ellen, Gigi Luk, Kathleen F. Peets \& Sujin Yang. 2010. Receptive vocabulary differences in monolingual and bilingual children. Bilingualism: Language and Cognition, 13, 525-531.

Biemiller, Andrew. 2001. Teaching Vocabulary: Early, direct, and sequential. The American Educator, 25(1), 24-28.

Biemiller, Andrew. 2003. Vocabulary: needed if more children are to read well. Reading Psychology, 24, 323.

Biemiller, Andrew \& Catherine Boote. 2006. An effective method for building vocabulary in primary grades. Journal of Educational Psychology, 98(1), 44-62.

Biemiller, Andrew \& Naomi Slonim. 2001. Estimating root word vocabulary growth in normative and advantaged populations: Evidence for a common sequence of vocabulary acquisition. Journal of Educational Psychology, 93, 498-520.

Bloom, Paul. 2000. How children learn the meanings of words. Cambridge, MA: MIT Press.

Bornstein, M. \& O. Maurice Haynes. 1998. Vocabulary competence in early childhood: Measurement, latent construct, and predictive validity. Child Development, 69, 654671.

Craik, Fergus I. M., \& Ellen Bialystok. 2006. Cognition through the lifespan cognition: Mechanisms of change. Trends in Cognitive Sciences, 10, 131-138.

D'Anna, Catherine A., Eugene B. Zechmeister \& James W. Hall. 1991. Toward a meaningful definition of vocabulary size. Journal of Reading Behavior, 23, 109-122.

Diller, Karl C. 1978. The Language Teaching Controversy. Rowley, Mass: Newbury House

Duke, Nell \& Joanne F. Carlisle. 2011. The development of comprehension. In Michael L. Kamil, P. David Pearson, Peter A. Afflerbach, \& Elizabeth B. Moje (eds.), Handbook of Reading Research, Vol. 4, 199-228. New York: Routledge.

Feldman Heidi M., Philip S. Dale, Thomas F. Campbell, D. Kathleen Colborn, Marcia KursLasky, Howard E. Rockette, \& Jack L. Paradise. 2005. Concurrent and predictive validity of parent reports of child language at ages 2 and 3 years. Child Development. 76(4), 856-868.

Fernandes, M.A., Craik. F.I.M, Bialystok, E., \& Sharyn Kreuger. 2007. Effect of Bilingualism, Aging, and Semantic Relatedness on Memory under Divided Attention. Canadian_Journal of Experimental Psychology, 61(2), 128-141.

Goulden, Rubin, Paul Nation, \& John Read. 1990. How large can a receptive vocabulary be? Applied Linguistics, 11 (4), 341-363.

Graves, Michael F. 2006. The Vocabulary Book. New York: Teachers College Press.

Hart, Betty \& Todd Risley. 1995. Meaningful differences in the everyday experience of young American children. Baltimore: Paul H. Brookes. 
Hart, Betty, \& Todd Risley. 2003. The early catastrophe: The 30 million word gap. American Educator, 27, 4-9.

Hartmann, George W. 1946. Further Evidence on the Unexpected Large Size of Recognition Vocabularies among College Students. Journal of Educational Psychology 37:436439.

Hatch, Evelyn. 1978. Discourse analysis and second language acquisition. In Haiti, E. (ed.) Second language acquisition: a book of readings. Newbury House, Rowley, Mass. 402-35.

Hazenberg, Suzanne, \& Jan H. Hulstijn. 1996. Defining a minimal receptive second-language vocabulary for non-native university students: An empirical investigation. Applied Linguistics, 17, 145-163.

$\mathrm{Hu}$, Marcella \& Paul Nation. 2000. Unknown vocabulary density and reading comprehension. Reading in a Foreign Language 13(1), 403-430.

Juel, Connie \& Rebecca Deffes. 2004. Making words stick. Educational Leadership, 61, 3034

Kirkpatrick, E.A. 1891. The number of words in an ordinary vocabulary. Science 18 (446), 107-108.

Konstantakis, Nikolas 2010. Constructing a Word List for the Academic Domain of Business. Unpublished $\mathrm{PhD}$ thesis, University of Swansea.

Lorge, Irving \& Jeanne S. Chall, J.S. 1963. Estimating the size of vocabularies of children and adults: An analysis of methodological issues. Journal of Experimental Education 32, 147-157.

Marchman, Virginia A. \& Anne Fernald. 2008. Speed of word recognition and vocabulary knowledge in infancy predict cognitive and language outcomes in later childhood. Developmental Science, 11(3): 9-16

Marzano, Robert J. 2004. Building background knowledge for academic achievement: Research on what works in schools. Alexandria, VA: Association for Supervision and Curriculum Development.

McLaughlin, Barry. 1978. The monitor model: Some methodological considerations. Language Learning. 28: 309-32.

Meara, Paul M. 1980. Vocabulary Acquisition: A Neglected Aspect of Language Learning. Language Teaching, 13 , pp 221-246

Meara, Paul M. \& Milton, James. 2003. X-lex: the Swansea levels test. Newbury. UK: Express Publishing.

Merriam, George \& Merriam, Charles. 1961. Webster's Third New International Dictionary. London: G. Bell. Springfield (Mass.).

Miller, George A. \& Patricia M. Gildea. 1987. How children learn words. Scientific American, 257 (3), 94-99.

Milton, James. 2009. Measuring second language vocabulary acquisition. Bristol: Multilingual Matters.

Nagy, William E. \& Richard C. Anderson. 1984. How many words are there in printed school English? Reading Research Quarterly, 19, 304-330.

Nagy, William E. 1988. Teaching vocabulary to improve reading comprehension. Newark, DE: International Reading Association

Nagy, William E. \& Patricia Herman. 1984. Limitations of vocabulary instruction. (Tech. Rep. No. 326).Champaign, IL: University of Illinois Center for the Study of Reading

Nagy, William E., Patricia A. Herman \& Richard C. Anderson. 1985. Learning words from context. Reading Research Quarterly 20, 233-253.

Nation, Paul. 2001. Learning vocabulary in another language. Cambridge:Cambridge University Press. 
Nation, Paul. 2006. How Large a Vocabulary Is Needed for Reading and Listening? The Canadian Modern Language Review 63(1), 59-81.

Nation, Paul. and Paul Meara. 2002. Vocabulary. In N. Schmitt (ed.) An Introduction to Applied Linguistics. London: Arnold.

Oller, D.Kimbrough, \& Rebecca E. Eilers (eds.). 2002. Language and literacy in bilingual children. Clevedon, England: Multilingual Matters

Ouellette, Gene. 2006. What's meaning got to do with it: The role of vocabulary in word reading and reading comprehension. The Journal of Educational Psychology 98, No.3, 554-566.

Pellicer-Sánchez, Ana \& Norbert Schmitt. 2010. Incidental vocabulary acquisition from an authentic novel: Do Things Fall Apart? Reading in a Foreign Language, 22(1), 31-55.

Schmitt, Norbert. 2007. Current perspectives on vocabulary teaching and learning. In J. Cummins and C. Davison (eds.), International Handbook of English language teaching: part II. NY: Springer, 827-841.

Schmitt, Norbert \& Michael McCarthy (eds.) 1997. Vocabulary: description, acquisition and pedagogy. Cambridge: Cambridge University Press

Seashore, R.H. \& Eckerson, L. 1940. The measurement of individual differences in general English vocabularies. Journal of Educational Psychology 31, 14-38.

Shaywitz, Bennett A., Theodore R. Holford, John M. Holahan, Jack M. Fletcher, Karla K. Stuebing, David J. Francis \& Sally A. Shaywitz. (1995) A Matthew effect for IQ but not for reading: Results from a longitudinal study. Reading Research Quarterly, 30, 894-906.

Shu, Hua, Richard C. Anderson \& Houcan Zhang. 1995. Incidental learning of word meanings while reading: a Chinese and American cross-cultural study. Reading Research Quarterly, 30, 76-95.

Snow, C.E., Tabors, P.O., Nicholson, P., \& Kurland, B. 1995. SHELL: Oral language and early literacy skills in kindergarten and first grade children. Journal of Research in Childhood Education, 10, 37-48.

Stanovich, Keith E. 1986. Matthew effects in reading: Some consequences of individual differences in the acquisition of literacy. Reading Research Quarterly, 21, 360-407.

Thorndike, Edward L. \& Irving Lorge. 1944. The teacher's Word Book of 30,000 Words. Teachers College, Columbia University, New York.

Treffers-Daller, Jeanine 2011. Operationalizing and measuring language dominance. International Journal of Bilingualism 15(2), 147-163.

Tymms, Peter, Christine Merrell \& Brian Henderson. 1997. 'The first year at school: a quantitative investigation of the attainment and progress of pupils', Educational Research and Evaluation, 3, 2, 101-18.

Waring, Robert \& Paul Nation. 2004. Second language reading and incidental vocabulary learning. Angles on the English-speaking world 4, 97-110.

White, Thomas G., Michael F. Graves \& Wayne H. Slater. 1990. Growth of vocabulary in diverse elementary schools: Decoding and word meaning. Journal of Educational Psychology, 82, 281-290.

Whitehurst, Grover J., F. Falco, Christopher J. Lonigan, Janet E. Fischel, Barbara DeBaryshe, Marta C. Valdez-Menchaca, \& M. Caulfield, 1988. Accelerating language development through picture-book reading. Developmental Psychology, 24, 552 - 558 